\title{
ARTICLE TrkB-dependent disinhibition of the nucleus accumbens is enhanced by ethanol
}

\author{
Mary H. Patton ${ }^{1}$, Katherine E. Padgett ${ }^{1}$, Paige N. McKeon ${ }^{1}$, Houman Qadir ${ }^{1}$, Michael S. Patton ${ }^{1}$, Chaoqi Mu${ }^{1}$, Bradley M. Roberts ${ }^{1}$ and
} Brian N. Mathur ${ }^{1}$

The nucleus accumbens is a critical integration center for reward-related circuitry and is comprised primarily of medium spiny projection neurons. The dynamic balance of excitation and inhibition onto medium spiny neurons determines the output of this structure. While nucleus accumbens excitatory synaptic plasticity is well-characterized, inhibitory synaptic plasticity mechanisms and their potential relevance to shaping motivated behaviors is poorly understood. Here we report the discovery of long-term depression of inhibitory synaptic transmission in the mouse nucleus accumbens core. This long-term depression is postsynaptically expressed, tropomyosin kinase B (TrkB) receptor-mediated, and augmented in the presence of ethanol. Our findings support the emerging view that TrkB signaling regulates inhibitory synaptic plasticity and suggest this mechanism in the nucleus accumbens as a target for ethanol modulation of reward.

Neuropsychopharmacology (2019) 44:1114-1122; https://doi.org/10.1038/s41386-019-0341-8

\section{INTRODUCTION}

Medium spiny projection neurons (MSNs) of the nucleus accumbens (NAc) encode motivated behavior through a dynamic interplay of excitatory, inhibitory, and modulatory synaptic inputs [1-4]. Drugs of abuse such as ethanol (EtOH) alter various forms of NAc excitatory synaptic plasticity to modulate drug seeking [5]. Despite the heavy influence of GABAergic transmission on MSNs [6], which arise from several intrinsic and extrinsic sources [1], native forms of inhibitory synaptic plasticity in the NAc remain unsolved.

Gating synaptic plasticity events across the striatal complex are membrane-voltage states. MSNs exhibit bi-stable membrane potentials: the depolarized "up state" $(\sim-60 \mathrm{mV})$ and hyperpolarized "down state" [7-9] ( - $80 \mathrm{mV})$. These distinct voltage states activate various voltage-gated calcium $\left(\mathrm{Ca}^{2+}\right)$ channels [10] and, as a result, enable voltage-dependent forms of synaptic plasticity $[11,12]$. For instance, at inhibitory synapses onto MSNs in the dorsal striatum, distinct forms of voltage-dependent inhibitory long-term depression (iLTD) exist: up state iLTD is mediated by the endocannabinoid (eCB) 2-arachidonoylglycerol (2-AG) while down state iLTD is putatively mediated by the eCB anandamide [12]. Given that eCB-mediated iLTD represent the predominant forms of plasticity in the dorsal striatum, this raises the possibility that eCBs acting through the type 1 cannabinoid receptor, CB1, also modulate NAC synapses in a voltage-dependent manner. Accordingly, a form of up state iLTD that is eCB-mediated and induced by unitary activation of $\mathrm{CB} 1$-expressing fast-spiking interneurons does exist in the NAc [13]. However, the expression of CB1 receptors is much lower in the NAc than the dorsal striatum [14, 15]. This suggests that other modulatory transmitters present in the NAc, including neuropeptides and monoamines, may support NAc inhibitory synaptic plasticity $[1,3,16]$.

In this study, we used whole-cell voltage-clamp recordings in acute mouse brain slices to discover a voltage-dependent iLTD onto NAc MSNs that is mediated by activation of the endogenous receptor for brain-derived neurotrophic factor (BDNF), tropomyosin receptor kinase $B$ (TrkB). Exploring an interaction of this system with the drug of abuse EtOH, we show that NAc-iLTD is enhanced in the presence of EtOH. These findings suggest that inhibition in the NAc is under plastic control and may participate in the encoding of EtOH reward.

\section{METHODS}

Experiments were carried out in accordance with the United States Public Health Service Guide for Care and Use of Laboratory Animals and approved by the University of Maryland, School of Medicine Institutional Animal Care and Use Committee.

Mice

Homozygous floxed-TrkB (Flx-TrkB) mice were maintained on a mixed C57BI/6J $\times$ FVB/N background [17]. Drd1a-tdTomato mice were bred on a C57BI/6J $\times$ SJL background (Jackson Laboratories). All other mice used for slice electrophysiology experiments were on a $\mathrm{C} 57 \mathrm{BI} / 6 \mathrm{~J}$ background. Animals were housed with littermates (2-5 per cage) under a regular light/dark cycle (lights on at 0700, off at $1900 \mathrm{~h}$ ) with ad libitum access to food and water. All experiments used female and male mice that were at least 2 months old.

Acute slice preparation

Mice were deeply anesthetized with isoflurane before rapid decapitation and brain removal. $250 \mu \mathrm{m}$ thick coronal slices were prepared in ice cold, $95 \%$ oxygen, $5 \%$ carbon dioxide (carbogen)bubbled modified aCSF (In mM: 194 sucrose, $30 \mathrm{NaCl}, 4.5 \mathrm{KCl}, 1$ $\mathrm{MgCl}_{2}, 26 \mathrm{NaHCO}_{3}, 1.2 \mathrm{NaH}_{2} \mathrm{PO}_{4}$, and 10 D-glucose) before incubating at $32{ }^{\circ} \mathrm{C}$ for 30 min in regular aCSF (in mM: $124 \mathrm{NaCl}$, $4.5 \mathrm{KCl}, 2 \mathrm{CaCl}_{2}, 1 \mathrm{MgCl}_{2}, 26 \mathrm{NaHCO}_{3}, 1.2 \mathrm{NaH}_{2} \mathrm{PO}_{4}$, and 10

${ }^{1}$ Department of Pharmacology, University of Maryland School of Medicine, 670 W. Baltimore St. HSF III 9179, Baltimore, MD 21201, USA

Correspondence: Brian N. Mathur (bmathur@som.umaryland.edu)

Received: 25 July 2018 Revised: 3 February 2019 Accepted: 6 February 2019

Published online: 13 February 2019 
D-glucose). Slices were stored at room temperature for the remainder of the day.

Whole-cell voltage-clamp electrophysiology

Slices were hemisected, placed into a recording chamber, and received constant perfusion of carbogen-bubbled aCSF containing $50 \mu \mathrm{M}$ DL-AP5 sodium salt and $5 \mu \mathrm{M}$ NBQX disodium salt or CNQX disodium salt that was temperature controlled to $29-31^{\circ} \mathrm{C}$. MSNs located in the core region of the NAc were visually targeted using Q-Capture Pro 7 software. MSNs were voltage clamped at $-60 \mathrm{mV}$ using a MultiClamp 700B Amplifier (Molecular Devices) throughout the experiment unless noted. IPSCs were recorded using borosilicate glass pipettes (2-5 M $\Omega$ resistance) filled with $\mathrm{CsCl}$ based internal pipette solution (in $\mathrm{mM}: 150 \mathrm{CsCl}, 10$ HEPES, 2 $\mathrm{MgCl}_{2}, 0.3 \mathrm{Na}-\mathrm{GTP}, 5 \mathrm{QX}-314,3 \mathrm{Mg}-\mathrm{ATP}$, and 0.2 BAPTA, osmolarity ranging from 305 to $310 \mathrm{mOsm}, \mathrm{pH} \sim 7.3)$. IPSCs were evoked every $20 \mathrm{~s}$ using a concentric bipolar stimulating electrode (World Precision Instruments) located $\sim 100 \mu \mathrm{m}$ away from the recording electrode. Signals were filtered at $2 \mathrm{kHz}$, digitized at $10 \mathrm{kHz}$ and acquired using Clampex 10.4.1.4 software (Molecular Devices). Electrically evoked-low-frequency stimulation (eLFS; $1 \mathrm{~Hz}, 240$ pulses) was delivered while holding MSNs at $-80 \mathrm{mV}$ (down state) after acquiring a stable baseline. To induce NAc-iLTD in the down state, the holding potential of the MSN was decreased from -60 $\mathrm{mV}$ to $-80 \mathrm{mV}$ by $-4 \mathrm{mV}$ increments every $4 \mathrm{~s}$ during the last $20 \mathrm{~s}$ before eLFS began. MSNs were returned to the up state $(-60 \mathrm{mV})$ by reversing the protocol during the first $20 \mathrm{~s}$ of the post-eLFS file. If the series resistance changed more than 15\% throughout the course of the experiment cells were discarded from analysis.

Viral injections

Bilateral stereotactic injections of AAV9-hSyn-cre-enhanced green fluorescent protein (eGFP; UPenn) into the NAc (A/P $+1.5 \mathrm{~mm}$ from bregma, $\mathrm{M} / \mathrm{L} \pm 0.8$ from midline, $\mathrm{D} / \mathrm{N}-3.5$ from top of brain) were performed on homozygous Flx-TrkB mice $[17,18]$ to selectively delete TrkB from all cells in the region.

Immunohistochemistry (IHC)

To verify injection sites following slice physiology recordings, NAC slices incubated in $4 \%$ PFA at $4{ }^{\circ} \mathrm{C}$ for at least 3 days and a shortened Brain BLAQ IHC procedure was performed [19]. To visualize eGFP fluorescence chicken-anti-GFP (Abcam ab13970; 1:2000) and AlexaFluor488 donkey-anti-chicken (Jackson ImmunoResearch 703-545-155; 1:500) antibodies were used. Slides were imaged using a Nikon Eclipse 90i.

\section{Statistical analysis}

Raw IPSC amplitudes were calculated on Clampfit 10.4.1.4, averaged per minute and expressed as a percent change from baseline. The final $5 \mathrm{~min}$ of all cells in the experiment were averaged and compared to the $5 \mathrm{~min}$ baseline using a two-tailed paired $t$-test (GraphPad Prism 6.01). To compare between experimental groups, the final $5 \mathrm{~min}$ of the recordings were averaged and compared using a two-tailed unpaired $t$-test. All data are reported as mean \pm SEM.

\section{Drugs}

All salts for aCSF, as well as sulpiride and 95\% EtOH were purchased from Sigma-Aldrich. DL-AP5 was purchased from Abcam. BAPTA (MW: 1004.03) was obtained from Molecular Probes. BDNF was purchased from PeproTech and Tocris Bioscience. All other drugs were purchased from Tocris Bioscience.

\section{RESULTS}

Nucleus accumbens inhibitory long-term depression (NAc-iLTD) Delivering electrical low-frequency stimulation (eLFS, $1 \mathrm{~Hz}$ for 240 pulses, Fig. 1a) locally to the core region of the NAc while voltage- clamping MSNs in the down state $(-80 \mathrm{mV})$ resulted in NAc-iLTD (Fig. 1b). To determine whether NAc-iLTD preferentially disinhibits the direct- or indirect pathways of the NAc, we induced NAc-iLTD in slices taken from the Drd1a-tdTomato reporter line of mice that express tdTomato in D1-dopamine receptor expressing MSNs (Fig. 1b). Down state NAc-iLTD occurred onto both D1-dopamine receptor expressing MSNs (Inhibitory postsynaptic current (IPSC) amplitude $=79.67 \pm 8.86 \%$ of baseline, $t=2.29, \mathrm{df}=9$ cells, $p=$ 0.047 , paired $t$-test) and putative D2-dopamine receptor expressing MSNs that were negative for tdTomato expression (IPSC amplitude $=75.99 \pm 7.01 \%$ of baseline, $t=3.43, \mathrm{df}=9, p=0.008$, paired $t$-test, Fig. 1b). NAc-iLTD was not due to changes in series resistance over time (Fig. 1b) and there was no effect of sex on NAc-iLTD expression: NAc-iLTD amplitude in females $=84.72 \pm$ $11.45 \%$ of baseline, $n=8$, NAc-iLTD amplitude in males $=74.9 \pm$ $6.83 \%$ of baseline, $n=7, t=0.76, \mathrm{df}=13, p=0.46$, unpaired $t$-test).

Down state iLTD in the dorsal striatum is eCB mediated [12] and, thus, we tested whether NAc-iLTD occurs through the same mechanism. Following at least $30 \mathrm{~min}$ of incubation in the CB1 antagonist AM251 (5 $\mu \mathrm{M})$, eLFS was delivered. Down state NAciLTD expression was not abolished in the presence of AM 251 (IPSC amplitude $=77.7 \pm 8.59 \%$ of baseline, $t=2.59, \mathrm{df}=5, p=$ 0.048 , paired $t$-test, Figure S1A). As corticostriatal LTD in the dorsal striatum is D2 dopamine receptor dependent, we examined whether NAc-iLTD is also sensitive to D2 receptor blockade. Including the D2 receptor antagonist sulpiride $(10 \mu \mathrm{M})$ in the artificial cerebrospinal fluid (aCSF) did not eliminate NAc-iLTD (IPSC amplitude in sulpiride $=74.38 \pm 6.71 \%$ of baseline, $t=3.82$, $\mathrm{df}=5, p=0.01$, paired $t$-test, Figure S1B). To test whether NAciLTD requires the activity of any postsynaptic G-protein-coupled receptors (GPCR), we included the GPCR-inhibitor, GDP- $\beta$-S (500 $\mu \mathrm{M})$ in the internal pipette solution. Inhibition of postsynaptic GPCRs did not affect NAc-iLTD expression (IPSC amplitude $=$ $81.63 \pm 6.24 \%$ of baseline, $t=2.94, \mathrm{df}=5, p=0.03$, paired $t$-test, Fig. 1c).

We hypothesized that activation of another receptor protein family, such as receptor tyrosine kinases, may be necessary for NAc-iLTD expression. We tested this by inhibiting the receptor for BDNF, TrkB, with cyclotraxin B $(2 \mu \mathrm{M})$ in the aCSF. This manipulation blocked the expression of down state NAc-iLTD (IPSC amplitude $=107.7 \pm 11.83 \%$ of baseline, $t=0.65, \mathrm{df}=13$, $p=0.53$, paired $t$-test, Fig. 1d). Cyclotraxin B blockade of NAciLTD was significantly different from control NAc-iLTD (control IPSC amplitude $=72.97 \pm 6.97 \%$ of baseline, versus cyclotraxin B IPSC amplitude $=107.7 \pm 11.83 \%$ of baseline, $t=2.28, \mathrm{df}=22$, $p=0.03$, unpaired $t$-test). Conditionally knocking out the TrkB receptor from the NAc by injecting a virus expressing crerecombinase (cre) into a line of mice in which the TrkB gene is flanked by loxP sites (Flx-TrkB, Fig. 1e) resulted in a failure to induce NAc-iLTD (IPSC amplitude $=94.96 \pm 7.87 \%$ of baseline, $t=0.64, \mathrm{df}=6, p=0.55$, paired $t$-test, Fig. 1f). Notably, there was no difference in the cumulative frequency distribution of the amplitude (Figure S1C) or frequency (Figure S1D) of spontaneous IPSC (sIPSC) events between TrkB knockout and control animals (sIPSC amplitude: Kolmogorov-Smirnov $D=$ $0.042, p=0.48$; sIPSC frequency: Kolmogorov-Smirnov $D=$ $0.002, p>0.999$ ).

The stability of LTD can be categorized into two forms: static and labile (for review, see [20]). In brief, labile LTD requires the presence of an agonist to maintain synaptic depression, while static LTD does not. To determine whether down state NAc-iLTD is static or labile, we applied cyclotraxin B onto slices after NAc-iLTD was established. GABAergic transmission remained depressed in the presence of cyclotraxin B (IPSC amplitude $25 \mathrm{~min}$ post induction $=66.52 \pm 11.76 \%$ of baseline, IPSC amplitude with cyclotraxin $B=67.68 \pm 10.51 \%$ of baseline, $t=0.10$, $\mathrm{df}=5, p=$ 0.92 , paired $t$-test, Fig. $1 \mathrm{~g}$ ), demonstrating that down state NAc- 
A

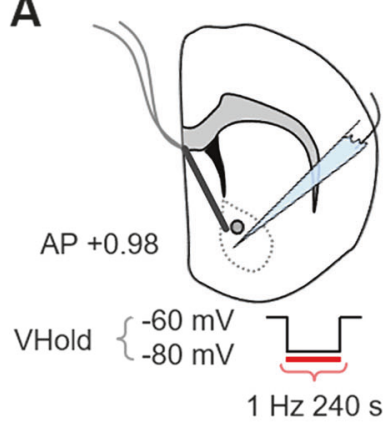

B

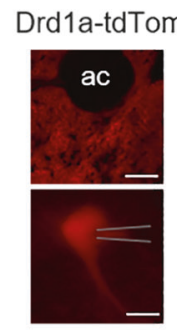

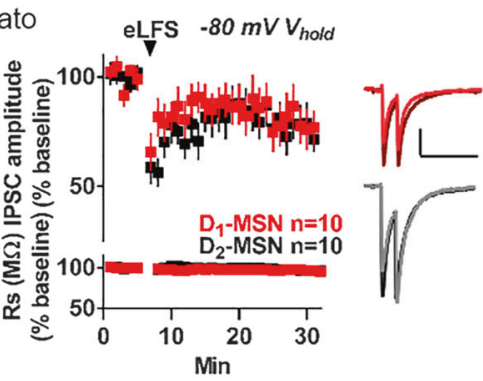

E

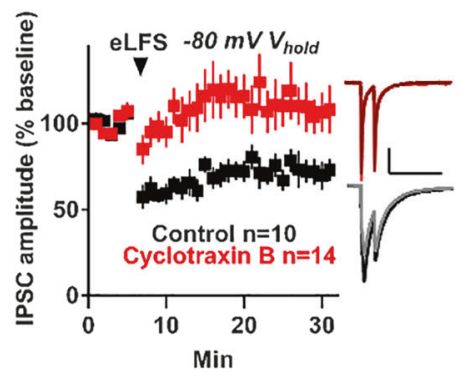

G

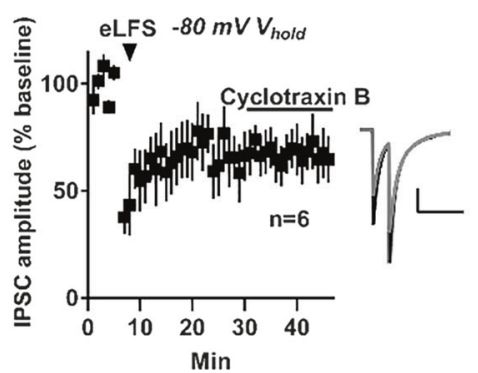

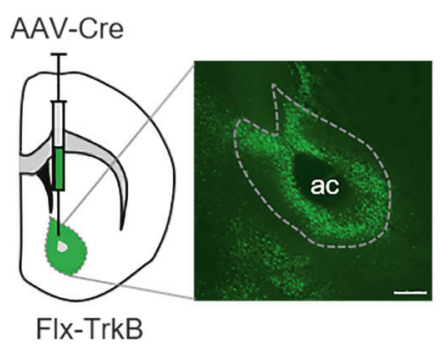

H

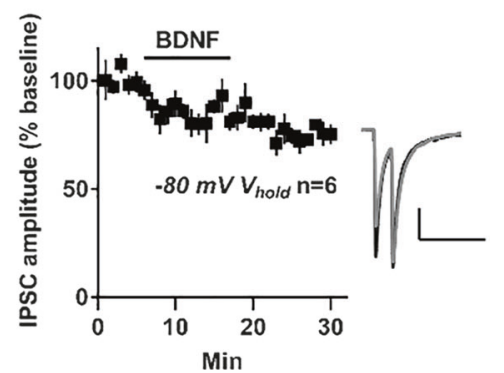

C

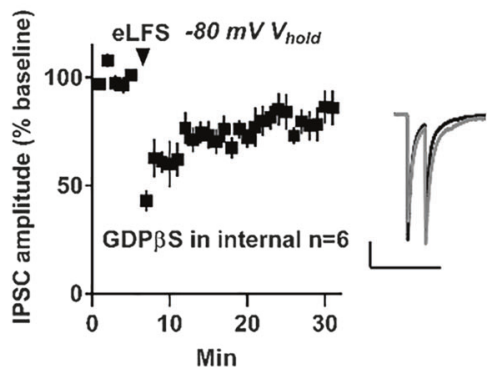

F

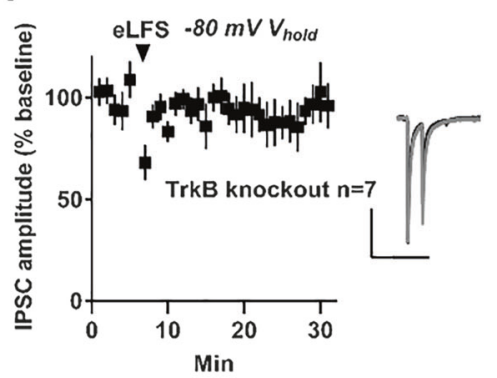

I

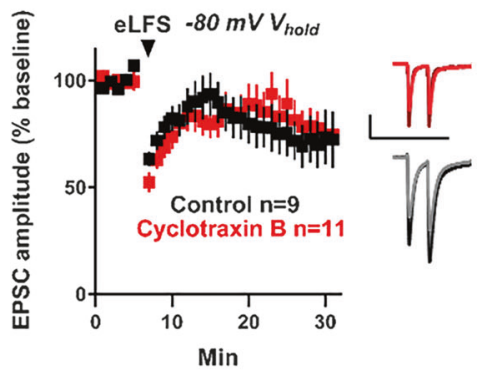

Fig. 1 Nucleus accumbens long-term depression of inhibitory synapses (NAc-iLTD) is tropomysin receptor kinase B (TrkB)-dependent. a Schematic representing the experimental configuration. b Left top: tdTomato expression under the Drd1a promoter. Left bottom: Representative patch onto a dopamine D1-receptor expressing medium spiny neuron (MSN). Scale bars: $125 \mu \mathrm{m}$ top and $20 \mu \mathrm{m}$ bottom. Right top: Electrical low-frequency stimulation (eLFS) delivered while voltage-clamping $\left(V_{\text {hold }}\right)$ D1- (red) and putative D2-dopamine receptor expressing (black) MSNs in the down state $\left(V_{\text {hold }}=-80 \mathrm{mV}\right)$ induced NAc-iLTD. Right bottom: NAc-iLTD in D1-expressing MSNs and D2expressing MSNs was not due to changes in series resistance (Rs). c Inclusion of GDP- $\beta-S(500 \mu M)$ in the internal pipette solution did not eliminate NAc-iLTD. d Bath application of the TrkB antagonist, cyclotraxin B $(2 \mu \mathrm{M})$ eliminated NAc-iLTD expression (red) compared to control conditions (black). e Left: Schematic of the experimental condition. Right: Expression of cre-recombinase in the NAc in floxed-TrkB mice (eGFP). Dashed line depicts the location of the NAc core. Scale bar: $250 \mu \mathrm{m}$. $\mathbf{f}$ Conditional deletion of TrkB from the NAc eliminated NAc-iLTD expression. g NAc-iLTD was stable; applying cyclotraxin B $(2 \mu \mathrm{M})$ after NAc-iLTD induction did not return inhibitory postsynaptic current (IPSC) amplitudes to baseline. $\mathbf{h}$ Acute application of exogenous brain-derived neurotrophic factor (BDNF, $4 \mathrm{nM}$ ) depressed inhibitory synaptic transmission onto MSNs while voltage-clamping MSNs at $-80 \mathrm{mV}$. i eLFS delivery while voltage clamping MSNs at $-80 \mathrm{mV}$ depressed excitatory transmission onto MSNs (black). This excitatory LTD was not TrkB dependent (red, $2 \mu$ M cyclotraxin B). Insets: Representative traces of the first $5 \mathrm{~min}$ (dark) and final $5 \mathrm{~min}$ (light) of the experiment. Scale bars for traces: $200 \mathrm{pA}, 200 \mathrm{~ms}$. EPSC excitatory postsynaptic current; AP anterior/posterior; ac anterior commissure. Data are represented as mean $\pm \mathrm{SEM}$

iLTD is static and that downstream signaling from TrkB is likely necessary for NAc-iLTD maintenance.

The sensitivity of NAc-iLTD to TrkB inhibition suggests that BDNF application should recapitulate synaptic depression. Applying BDNF (4 nM) while voltage-clamping MSNs in the down state depressed inhibition onto MSNs (IPSC amplitude $=75.09 \pm 2.24 \%$ of baseline, $t=11.11, \mathrm{df}=5, p=0.0001$, paired $t$-test, Fig. $1 \mathrm{~h}$ ). To determine if BDNF depresses excitatory transmission onto MSNs, we applied BDNF onto NAc slices in the presence of picrotoxin (50 $\mu \mathrm{M})$ to block $\mathrm{GABA}_{\mathrm{A}}$-receptor-mediated currents and found that, similar to inhibitory transmission onto MSNs, BDNF depressed excitatory transmission (Excitatory postsynaptic current (EPSC) amplitude $=60.83 \pm 8.43 \%$ of baseline, $t=4.64, \mathrm{df}=4, p=0.0097$, paired $t$-test, Figure S1E). Because BDNF depressed excitatory synaptic transmission in the NAc, we investigated if TrkBdependent LTD occurs at excitatory synapses in the NAC in response to eLFS. We delivered eLFS to slices in aCSF containing picrotoxin $(50 \mu \mathrm{M})$ and found that eLFS induced an excitatory long-term depression (eLTD; EPSC amplitude $=71.46 \pm 10.64 \%$ of baseline, $t=2.68, \mathrm{df}=8, p=0.028$, paired $t$-test, Fig. $1 \mathrm{i})$. However, this eLTD was not cyclotraxin B-sensitive (EPSC amplitude in cyclotraxin $B=76.86 \pm 8.43 \%$ of baseline, $t=2.74, \mathrm{df}=10, p=$ 0.02 , paired $t$ test; control versus cyclotraxin $\mathrm{B}: t=0.403, \mathrm{df}=18$, $p=0.69$, unpaired $t$-test, Fig. 1i).

NAc-iLTD is postsynaptically expressed We next analyzed if NAc-iLTD is expressed pre- or postsynaptically by analyzing the cumulative frequency distribution of the 
amplitude and frequency of sIPSC events before and after iLTD induction. The cumulative frequency distribution of sIPSC event amplitude was significantly different than that of sIPSC amplitudes following NAc-iLTD induction (Kolmogorov-Smirnov $D=0.15, p<$ 0.0001 , Fig. $2 a, b)$, while the distribution of sIPSC event frequency was not (Kolmogorov-Smirnov $D=0.009, p<0.99$, Fig. 2a, b). Further, paired-pulse ratio (PPR) analysis prior to eLFS delivery was not significantly different from PPR 25 min following eLFS delivery in the down state, but was different at the 5 min time point following eLFS delivery (baseline PPR $=0.94 \pm 0.05$; PPR at minutes $6-10=1.06 \pm 0.08$, minutes $25-30$ post iLTD induction $P P R=0.99$ $\pm 0.06, F(1.61,30.62)=9.94, p=0.001$, RM one-way ANOVA, Fig. 2d). Accordingly, the coefficient of variation (CV) of IPSC amplitude before NAc-iLTD induction did not differ 25 min after NAc-iLTD induction, but did differ the first $5 \mathrm{~min}$ following (baseline CV $=0.18 \pm 0.01, \mathrm{CV}$ minutes $6-10=0.26 \pm 0.02, \mathrm{CV}$ minutes $25-30=0.2 \pm 0.02, F(1.63,19.56)=10.56, p=0.001$, RM one-way ANOVA, Fig. 2e). Neither the PPR or CV of IPSC amplitude were changed $5 \mathrm{~min}$ or $25 \mathrm{~min}$ following BDNF application (PPR before $\mathrm{BDNF}=0.83 \pm 0.03, \mathrm{PPR}$ minutes $6-10=0.8 \pm 0.07, \mathrm{PPR}$ minutes 25-30 after $\mathrm{BDNF}=0.8 \pm 0.08, F(1.38,6.89)=0.06, p=$ 0.88 , RM one-way ANOVA, Fig. 2f; Baseline CV $=0.23 \pm 0.05$, CV $6-10 \mathrm{~min}$ post-BDNF $=0.21 \pm 0.04, \mathrm{CV} 25-30 \mathrm{~min}$ post-BDNF $=0.2$ $\pm 0.04, F(1.49,7.43)=0.61, p=0.52$, RM one-way ANOVA, Fig. $2 \mathrm{~g}$ ). These findings suggest the mechanism underlying late-stage-NAciLTD is expressed postsynaptically while the short term synaptic depression immediately following eLFS is presynaptically mediated.

TrkB signals through various downstream signaling cascades [1], one of which is the mitogen-activated protein kinaseextracellular signal-regulated kinase (MEK-ERK) pathway. To test whether MEK activity is necessary for NAc-iLTD, we included the MEK inhibitor U0126 $(2 \mu \mathrm{M})$ in the internal pipette solution. NAc-iLTD was eliminated in the presence of U0126 (U0126 IPSC amplitude $=98.36 \pm 11.71 \%$ of baseline, $t=0.14$, $\mathrm{df}=6$ cells, $p=0.89$, paired $t$-test; versus control NAc-iLTD amplitude $=$ $68.15 \pm 5.90 \%$ of baseline, $t=2.30, \mathrm{df}=12, p=0.04$, unpaired $t$ test, Fig. 2h). Testing an alternative downstream pathway recruited by TrkB signaling, we found that blocking phospholipase $C$ (PLC) activity with $1 \mu \mathrm{M}$ U73122 in the internal pipette solution had no effect on NAc-iLTD (IPSC amplitude $=76.45 \pm$ $8.91 \%$ of baseline, $t=2.64, \mathrm{df}=6, p=0.04$, paired $t$-test, Fig. $2 \mathrm{i}$ ). TrkB signaling through MEK activity typically exerts changes in plasticity through protein synthesis [1]. Thus, we tested whether NAc-iLTD requires protein synthesis by incubating NAc slices in the protein synthesis inhibitor cycloheximide $(25 \mu \mathrm{M})$ for at least $30 \mathrm{~min}$ before delivering eLFS. Cycloheximide did not block NAC-iLTD, suggesting this form of plasticity does not require protein synthesis (IPSC amplitude $=77.97 \pm 8.03 \%$ of baseline, $t=2.74, \mathrm{df}=8, p=0.03$, paired $t$-test, Fig. $2 \mathrm{j}$ ), however incubating slices with cycloheximide prevented the expression of eCB-dependent corticostriatal LTD in the dorsal striatum, which does require protein synthesis [21] (Control IPSC amplitude $=54.94 \pm 8.57 \%$ of baseline, $t=5.26, \mathrm{df}=4, p=$ 0.006 , paired $t$-test; IPSC amplitude in cycloheximide $=$ $91.72 \pm 6.2 \%$ of baseline, $t=1.34, \mathrm{df}=4, p=0.25$, paired $t$-test; cycloheximide versus control: $t=3.48, \mathrm{df}=8, p=0.008$, unpaired $t$-test, Figure S1F).

Because TrkB signaling can lead to dynamin-mediated $G_{A B A} A^{-}$ receptor endocytosis [22], we tested whether dynamin-mediated endocytosis is necessary for NAc-iLTD by including a dynamininhibitory peptide (DIP, $50 \mu \mathrm{M})$ in the internal pipette solution. Inclusion of DIP blocked NAc-iLTD, whereas a scrambled version of the peptide (DIPS, $50 \mu \mathrm{M}$ ) did not (DIP IPSC amplitude $=91.58 \pm$ $8.82 \%$ of baseline, $t=0.95, \mathrm{df}=5, p=0.38$, paired $t$-test; DIPS IPSC amplitude $=68.17 \pm 4.65 \%$ of baseline, $t=6.85, \mathrm{df}=5, p=0.001$, paired $t$-test; DIP versus DIPS internal: $t=2.35, \mathrm{df}=10, p=0.04$, unpaired $t$-test, Fig. $2 \mathrm{k}$ ).
NAc-iLTD is voltage-state dependent

Because iLTD in the dorsal striatum is membrane-voltage-state dependent [12], we delivered eLFS while voltage-clamping MSNs in the up state $(-60 \mathrm{mV})$. This did not depress GABAergic transmission onto NAC MSNs (IPSC amplitude $=87.05 \pm 12.4 \%$ of baseline, $t=1.04, \mathrm{df}=6$ cells, $p=0.34$, paired $t$-test, Fig. 3a), suggesting NAc-iLTD is membrane-voltage dependent. Testing the voltage-dependence of BDNF-induced synaptic depression, application of BDNF while voltage-clamping MSNs in the up state did not depress inhibition onto MSNs (IPSC amplitude $=90.79 \pm$ $5.29 \%$ of baseline, $t=1.74, \mathrm{df}=4, p=0.16$, paired $t$-test, Fig. $3 \mathrm{~b}$ ). To verify that NAc-iLTD is in fact voltage dependent and not due to a sampling error, we delivered eLFS while voltage-clamping MSNs in the up state, followed by delivery of eLFS while voltageclamping MSNs in the down state. Inhibition onto MSNs did not depress when MSNs were held in the up state during eLFS delivery (IPSC amplitude $=91.36 \pm 6.78 \%$ of baseline, $t=1.28$, $\mathrm{df}=6$ cells, $p=0.25$, paired $t$-test), but did depress when MSNs were subsequently held in the down state during eLFS (IPSC amplitude $=73.68 \pm 4.66 \%$ of baseline, $t=5.65, \mathrm{df}=6$ cells, $p=$ 0.001 , paired $t$-test, Fig. 3c).

The voltage-dependence of distinct forms of iLTD in the nearby dorsal striatum is gated by postsynaptic $\mathrm{Ca}^{2+}[12]$. To test whether the voltage-dependence of NAc-iLTD is similarly $\mathrm{Ca}^{2+}$ dependent, we included a high concentration of the $\mathrm{Ca}^{2+}$ chelator BAPTA (20 $\mathrm{mM}$ ) in the internal pipette solution. Inhibition onto MSNs was still depressed by eLFS when MSNs were held in the down state in the presence of $20 \mathrm{mM}$ BAPTA (IPSC amplitude $=82.06 \pm 5.48 \%$ of baseline, $t=3.28, \mathrm{df}=8, p=0.01$, paired $t$-test, Fig. $3 \mathrm{~d}$ ), suggesting that NAc-iLTD occurs in a $\mathrm{Ca}^{2+}$-independent manner. However, PPR analysis following NAc-iLTD induction with $20 \mathrm{mM}$ BAPTA revealed this LTD no longer contains a presynaptic component (baseline PPR $=0.96 \pm 0.09$, PPR minutes $6-10=$ $0.86 \pm 0.05$, PPR minutes $25-30=0.96 \pm 0.11, F(1.37,9.6)=2.5$, $p=0.14$, RM one-way ANOVA, Fig. 3e). Because the down state of MSNs is beyond the activation threshold for L-type voltage-gated $\mathrm{Ca}^{2+}$ channels (VGCC) [10] and down state NAc-iLTD was insensitive to postsynaptic BAPTA loading, we predicted that the expression of down state NAc-iLTD would be unaffected in the presence of the L-type VGCC inhibitor, nifedipine. Indeed, inhibition onto MSNs was still depressed by eLFS when MSNs were held in the down state in the presence of nifedipine (30-60 $\mu \mathrm{M}$ ) (IPSC amplitude $=82.16 \pm 3.42 \%$ of baseline, $t=5.21$, $\mathrm{df}=4, p=0.007$, paired $t$-test, Fig. 3f).

Similar to the dorsal striatum [12], when eLFS was delivered while MSNs were held in the up state, the inclusion of $20 \mathrm{mM}$ BAPTA unmasked NAc-iLTD (IPSC amplitude $=68.27 \pm 4.14 \%$ of baseline, $t=7.67, \mathrm{df}=5$, paired $t$-test, $p=0.0006$, paired $t$-test; versus control internal solution: $t=2.52, \mathrm{df}=10, p=0.03$, unpaired $t$-test, Fig. $3 \mathrm{~g}$ ). Because the activation threshold of L-type VGCC is within the MSN up state membrane potential range [10], we predicted that up state NAc-iLTD would be unmasked by blocking L-type VGCC with nifedipine. Up state NAc-iLTD was unmasked in the presence of nifedipine (IPSC amplitude $=70.48 \pm 10.49 \%$ of baseline, $t=2.81$, $\mathrm{df}=5, p=0.04$, paired $t$-test; versus control aCSF: $t=2.6, \mathrm{df}=9$, $p=0.03$, unpaired $t$-test, Fig. $3 h$ ).

The effect of EtOH on NAc-iLTD

Because disinhibiting the NAc may be associated with rewardrelated behaviors, we investigated whether EtOH interacts with NAc-iLTD. To test this, we first applied EtOH onto NAc slices at two different concentrations (a low concentration: $10 \mathrm{mM}$, and a high concentration: $50 \mathrm{mM}$ ) while voltage clamping MSNs in the up or down state. Delivering paired electrical stimulation pulses eliminates EtOH-induced LTD in the dorsal striatum [23]. Therefore, we delivered single electrical pulses to determine the effect of EtOH on inhibitory synaptic strength in the NAc. Acute application of $10 \mathrm{mM} \mathrm{EtOH}$ alone did not depress inhibition onto 
A

Baseline

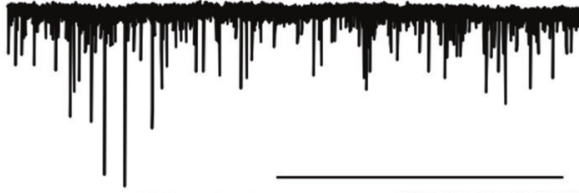

$25 \mathrm{~min}$ post eLFS

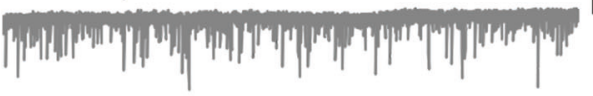

D

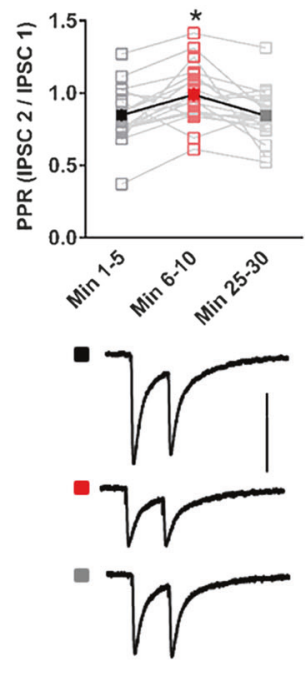

H
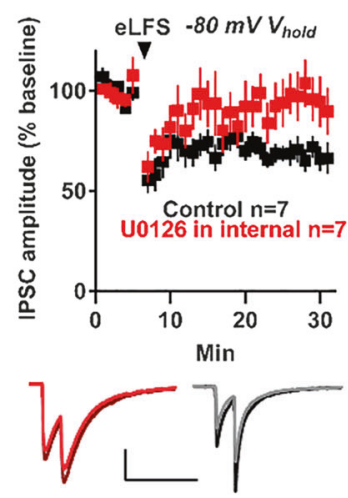

B
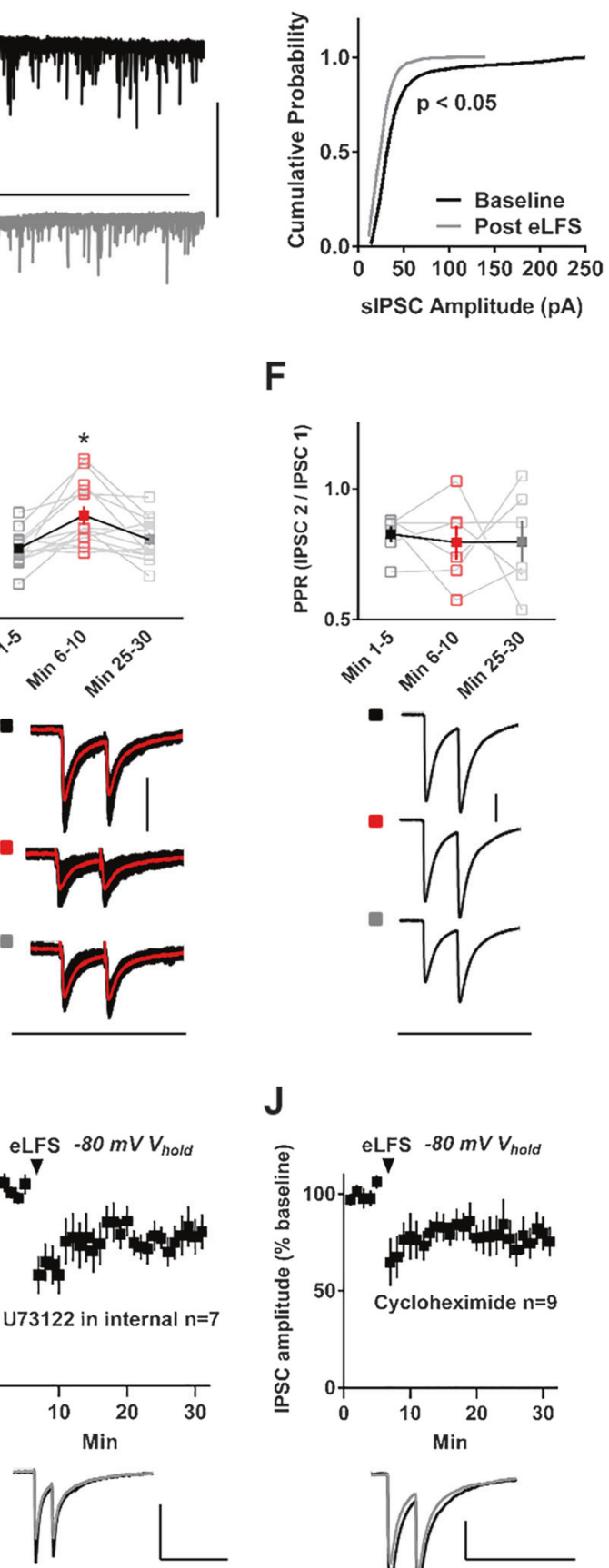

F

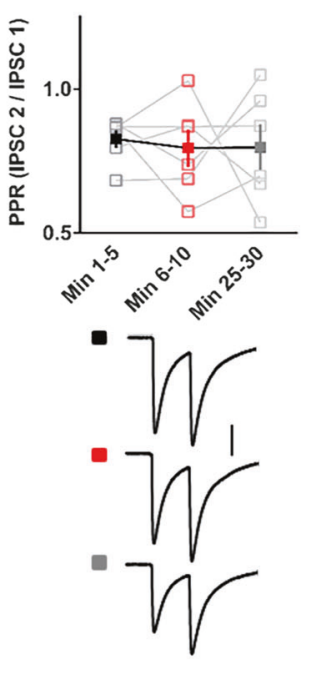

J

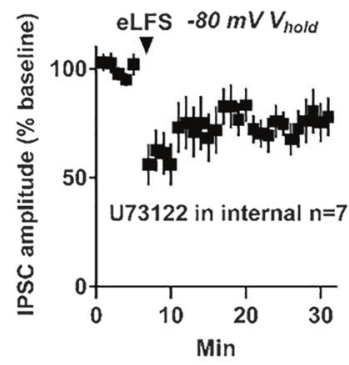

E

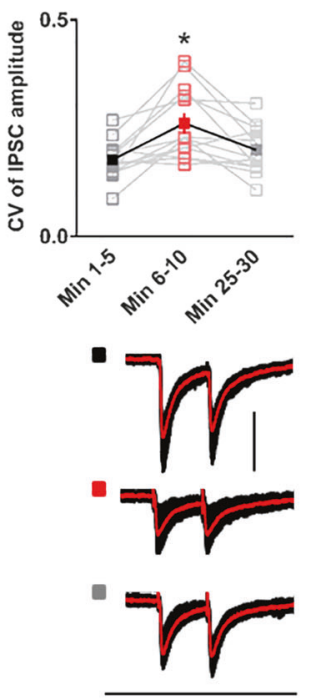

I

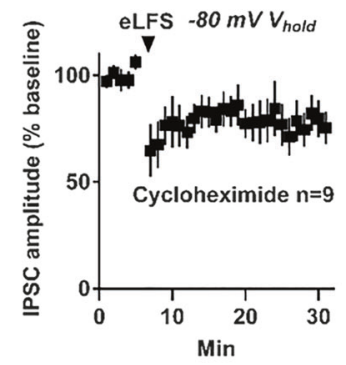

C

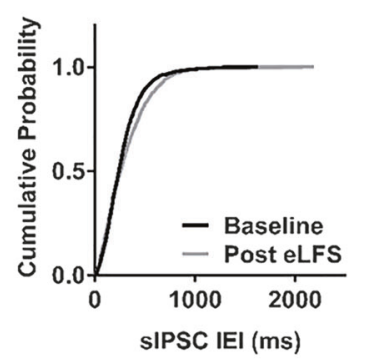

G

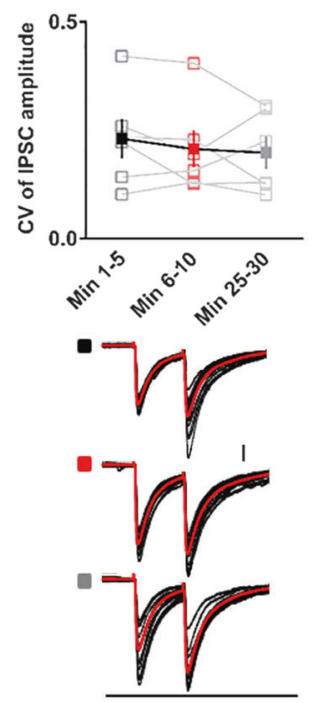

K
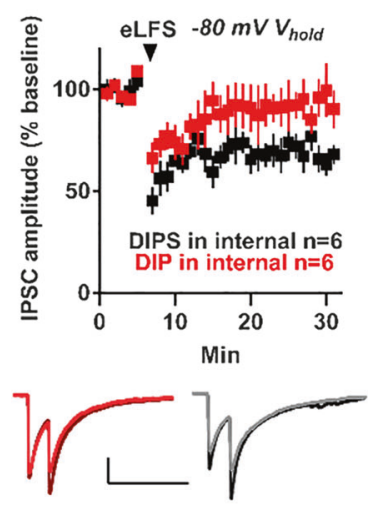

Fig. 2 NAc-iLTD is postsynaptically expressed. a Representative traces of spontaneous IPSC events (sIPSC) before (black) and after NAc-iLTD induction (gray). Scale bars: 200 pA, $50 \mathrm{~s}$. b The cumulative frequency distribution (CFD) of sIPSC amplitudes after NAc-iLTD induction (gray) differed from baseline (black). c The CFD of the frequency of sIPSC events before and after NAc-iLTD induction were not different. $\mathbf{d}$ Top: The paired-pulse ratio (PPR) before (black) and $25 \mathrm{~min}$ after (gray) NAc-iLTD induction were not different, but was different the first 5 min after induction (red). Open squares are individual cells; filled squares represent the mean PPR. Bottom: Representative traces at each time point. e Top: The coefficient of variation (CV) did not differ before and $25 \mathrm{~min}$ after LFS delivery. CV was significantly different the first 5 min following LFS delivery. Bottom: Representative traces at each time point; the red trace is the average of all the traces at that time point. $f$ Top: PPR at minutes 6-10 and 25-30 did not differ following BDNF application. Bottom: Representative traces at each time point. g Top: CV of IPSC amplitude following BDNF application at minutes 25-30 did not differ from baseline values or minutes 6-10. Bottom: Representative traces at each time point; the red trace is the average of all the traces at that time point. $\mathbf{h}$ Including the MEK inhibitor, U0126 ( $2 \mu \mathrm{M})$ in the internal pipette solution blocked NAc-iLTD induction (red), compared to controls (black). $\mathbf{i}$ Inclusion of the PLC inhibitor, U73122 (1 $\mu$ M) in the internal pipette solution did not eliminate NAc-iLTD. $\mathbf{j}$ Inhibiting protein synthesis with cycloheximide $(25 \mu \mathrm{M})$ in the artificial cerebrospinal fluid (aCSF) did not alter NAc-iLTD expression. $\mathbf{k}$ Inhibiting dynamin-mediated endocytosis with a dynamin-inhibitory peptide (DIP, $50 \mu M)$ in the internal pipette solution blocked NAc-iLTD (red), while including a scrambled version of this peptide (DIPS, $50 \mu \mathrm{M}$ ) did not (black). Insets: Representative traces of the first $5 \mathrm{~min}$ (dark) and final $5 \mathrm{~min}$ (light) of the experiment. Scale bars: 200 pA, $200 \mathrm{~ms}$, unless noted otherwise. ${ }^{*} p<0.05$. Data are represented as mean \pm SEM 
A

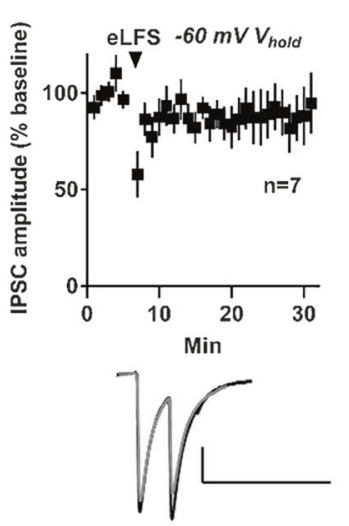

E

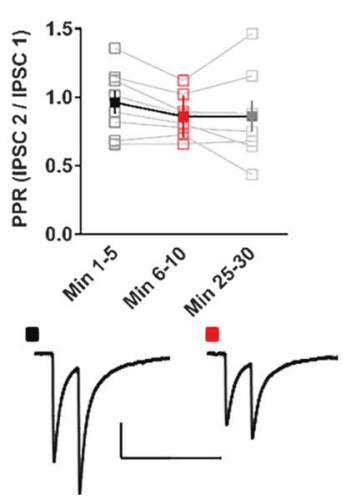

B

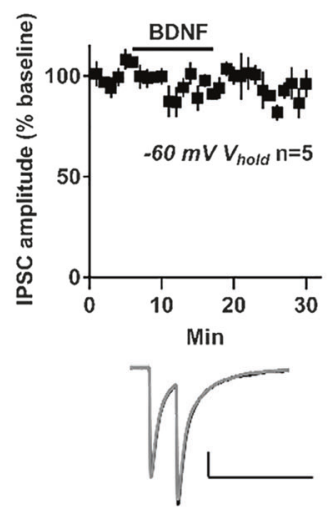

$\mathbf{F}$
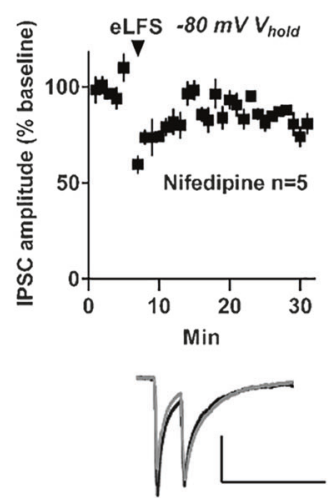

C
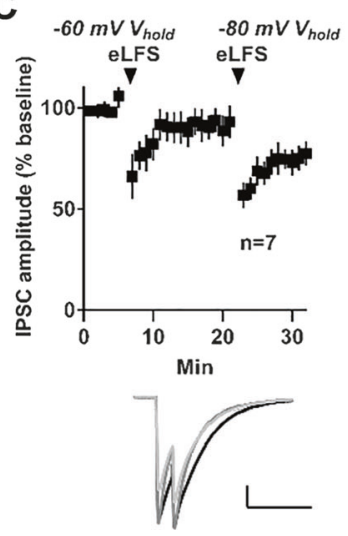

G
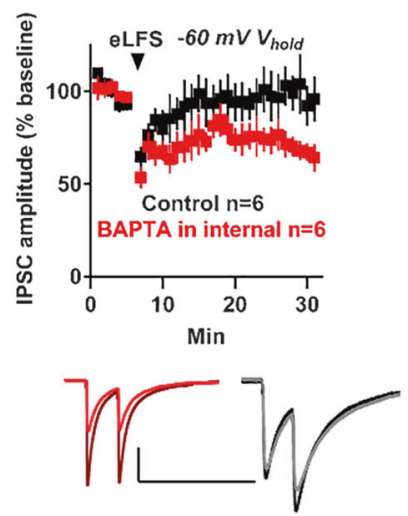

D
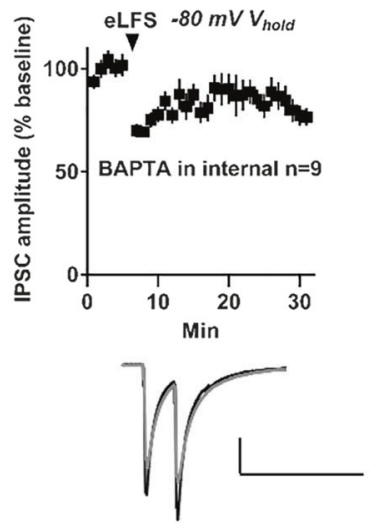

$\mathrm{H}$
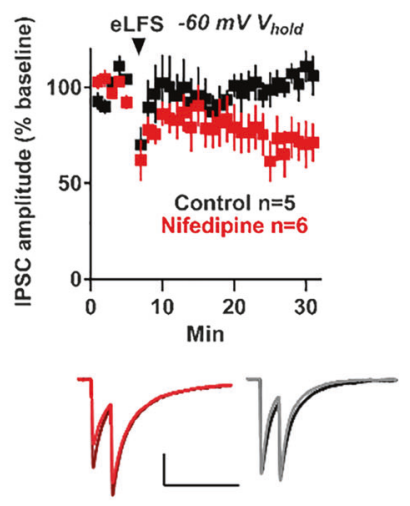

Fig. 3 NAC-iLTD membrane-voltage-state dependence is dictated by L-type voltage-gated calcium $\left(\mathrm{Ca}^{2+}\right)$ channels. a eLFS delivered while voltage-clamping MSNs in the up state $\left(V_{\text {hold }}=-60 \mathrm{mV}\right)$ did not induce NAc-iLTD. b Acute application of BDNF $(4 \mathrm{nM})$ while voltage clamping MSNs at $-60 \mathrm{mV}$ did not produce iLTD. $\mathbf{c}$ Down state NAc-iLTD occurred in MSNs that did not express up state NAc-iLTD. $\mathbf{d}$ Inclusion of the Ca ${ }^{2}$ + chelator, BAPTA $(20 \mathrm{mM})$ in the internal pipette solution did not alter down state NAc-iLTD. e PPR following NAc-iLTD induction with a high BAPTA concentration is not different across the experiment. Open squares are individual cells; filled squares represent the mean PPR. $f$ The Ltype $\mathrm{Ca}^{2+}$-channel blocker, nifedipine $(30-60 \mu \mathrm{M})$ did not alter down state NAc-iLTD. g Including BAPTA (20 mM) in the internal pipette solution unmasked the expression of up state NAc-iLTD (red), compared to controls (black). h Nifedipine (30-60 $\mu \mathrm{M})$ also unmasked up state NAc-iLTD (red), compared to control aCSF (black). Insets: Representative traces of the first 5 min (dark) and final 5 min (light) of the experiment. Scale bars: $200 \mathrm{pA}, 200 \mathrm{~ms}$. Data are represented as mean \pm SEM

NAc MSNs when voltage clamped at either membrane-voltage state (IPSC amplitude for up state $=100.4 \pm 14.11 \%$ of baseline, $t=0.03, \mathrm{df}=5$ cells, $p=0.98$, paired $t$-test; IPSC amplitude for down state $=92.65 \pm 7.86 \%$ of baseline, $t=0.93, \mathrm{df}=5, p=0.39$, paired $t$-test, Fig. 4a). Similarly, acute application of a high dose of $\mathrm{EtOH}(50 \mathrm{mM})$ did not depress inhibition onto NAc MSNs while voltage clamped at the up or down state (IPSC amplitude for up state $=97.86 \pm 2.14 \%$ of baseline, $t=0.99, \mathrm{df}=7, p=0.35$, paired $t$-test; IPSC amplitude for down state $=104.3 \pm 10.1 \%$ of baseline, $t=0.43, \mathrm{df}=6, p=0.68$, paired $t$-test, Fig. $4 \mathrm{~b}$ ). However, delivering eLFS to slices in $10 \mathrm{mM}$ EtOH significantly augmented the magnitude of IPSC amplitude depression (IPSC amplitude in 10 $\mathrm{mM} \mathrm{EtOH}=56.23 \pm 7.52 \%$ of baseline, $t=5.82, \mathrm{df}=7, p=0.0007$, paired $t$-test; versus control aCSF: $t=2.22, \mathrm{df}=15, p=0.04$, unpaired $t$-test, Fig. 4c). Enhancement of NAc-iLTD similarly occurred after incubating slices in a higher concentration of EtOH ( $50 \mathrm{mM}$, IPSC amplitude $=50.91 \pm 10.71 \%$ of baseline, $t=4.58$, $\mathrm{df}=6, p=0.0038$, paired $t$-test; verses control aCSF: $t=2.35, \mathrm{df}=$ $13, p=0.04$, unpaired $t$-test, Fig. $4 d$ ). This enhanced NAc-iLTD was not eliminated upon removal of EtOH (IPSC amplitude in $50 \mathrm{mM}$ $\mathrm{EtOH}=69.69 \pm 5.66 \%$ of baseline, IPSC amplitude in regular $\mathrm{aCSF}=64.81 \pm 6.81 \%$ of baseline, $t=0.83, \mathrm{df}=5, p=0.44$, paired $t$-test, Figure $\mathrm{S} 1 \mathrm{G})$. There was no difference in the magnitude of the enhancement of NAc-iLTD induced in $10 \mathrm{mM}$ or $50 \mathrm{mM} \mathrm{EtOH}$, suggesting this effect is not dose-dependent (Concentration: $F(1$, $13)=0.72, p=0.41$, Time: $F(29,377)=12.54, p<0.0001$, Two-way Time $\times$ Concentration mixed ANOVA). The inclusion of either concentration of $\mathrm{EtOH}$ in the bath eliminated the presynaptic component to NAc-iLTD (for $10 \mathrm{mM}$ : baseline PPR $=0.87 \pm 0.03$, PPR minutes $6-10=0.92 \pm 0.02$, PPR minutes $25-30=0.89 \pm 0.03$, $F(1.31,5.24)=0.8, p=0.45$, RM one-way ANOVA, Fig. 4e; for 50 $\mathrm{mM}$ : Baseline PPR $=0.97 \pm 0.16$, PPR minutes $6-10=0.91 \pm 0.14$, PPR minutes $25-30=0.99 \pm 0.1, F(1.72,6.88)=0.24, p=0.76, \mathrm{RM}$ one-way ANOVA, Fig. 4f). Moreover, there was no effect of the animal's sex on $50 \mathrm{mM}$ EtOH-induced enhancement of NAc-iLTD (IPSC amplitude in females $=52.47 \pm 7.03 \%$ of baseline, $n=8$, IPSC amplitude in males $=55.91 \pm 4.46 \%$ of baseline, $n=9, t=0.42$, $\mathrm{df}=15, p=0.68$, unpaired $t$-test).

The enhancement of NAc-iLTD by $50 \mathrm{mM}$ EtOH was eliminated in the presence of cyclotraxin B (IPSC amplitude $=105.7 \pm 9.20 \%$ of baseline, $t=0.62, \mathrm{df}=5, p=0.56$, paired $t$-test, Fig. $4 \mathrm{~g}$ ) and PPR did not change throughout the course of the experiment in the presence of cyclotraxin $B$ (baseline PPR $=1.16 \pm 0.21$, PPR minutes $6-10=1.05 \pm 0.14, \quad P P R$ minutes $25-30=1.25 \pm 0.11, \quad F(1.89$, $9.45)=1.24, p=0.33$, RM one-way ANOVA, Fig. 4h). To determine the possible involvement of the EtOH metabolite acetaldehyde in enhanced NAc-iLTD, we applied acetaldehyde $(1 \mu \mathrm{M})$ to the slice and measured the change in IPSC amplitude. Acute application of 
A

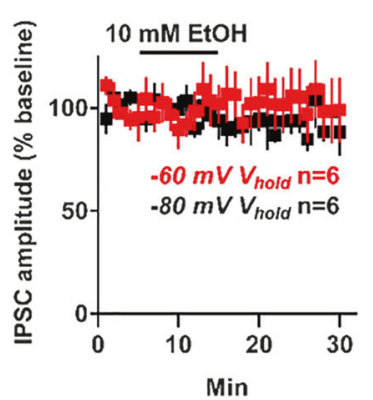

C

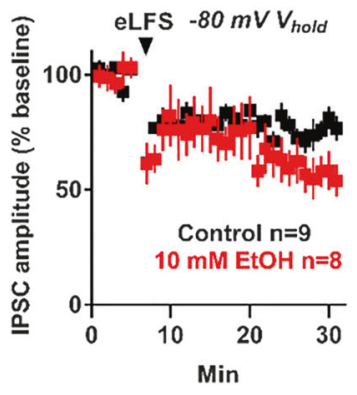

\section{E}

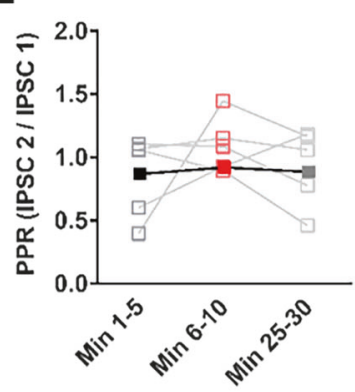

G

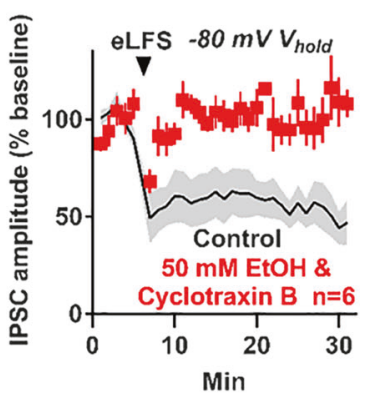

B

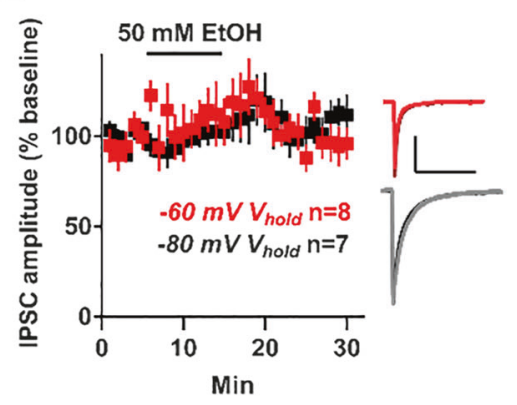

D

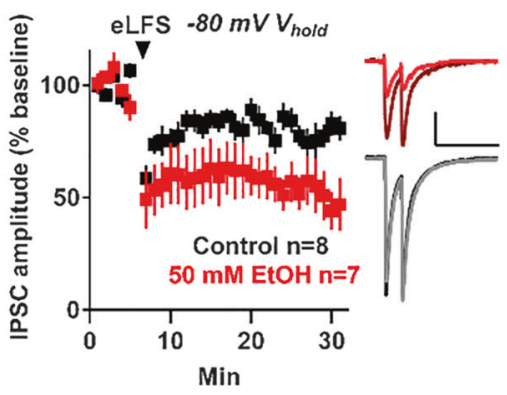

$\mathbf{F}$
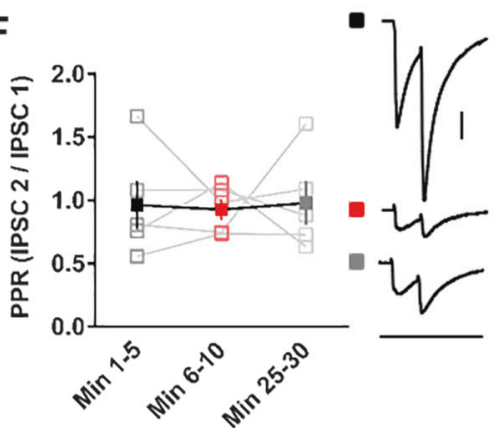

$\mathrm{H}$

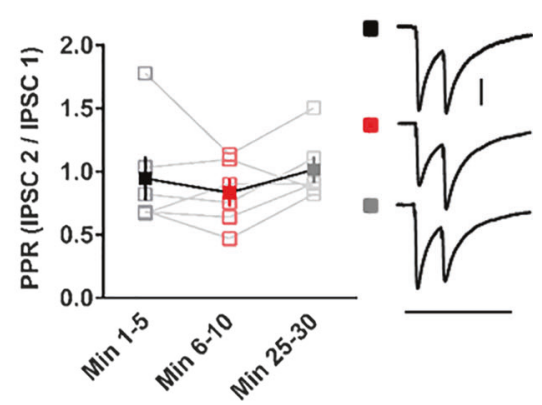

Fig. 4 Ethanol (EtOH) enhances NAc-iLTD. a Acute application of $10 \mathrm{mM}$ EtOH did not depress synaptic inhibition onto MSNs when voltage clamped at $-60 \mathrm{mV}$ (red) or $-80 \mathrm{mV}$ (black). b Acute application of a higher dose of EtOH (50 mM) did not depress inhibitory transmission onto MSNs when voltage clamped at either $-60 \mathrm{mV}$ (red) or $-80 \mathrm{mV}$ (black). c Incubating slices in $10 \mathrm{mM}$ EtOH enhanced NAc-iLTD (red) compared to control aCSF (black). d The presence of a higher concentration of EtOH $(50 \mathrm{mM})$ in the aCSF enhanced the magnitude of NAciLTD (red) compared to control aCSF (black). e Left: The mean PPR was not different at any time point following NAc-iLTD induction in the presence of $10 \mathrm{mM}$ EtOH. Right: Representative traces for each time point. $\mathbf{f}$ Left: The mean PPR was not significantly different between any time point following NAc-iLTD induction in the presence of $50 \mathrm{mM}$ EtOH. Right: Representative traces for each time point. g $50 \mathrm{mM}$ EtOHenhanced NAc-iLTD is eliminated in the presence of cyclotraxin B $(2 \mu \mathrm{M}$, red). Black line $( \pm S E M$, gray) represents the $50 \mathrm{mM}$ EtOH-induced enhancement of NAc-iLTD from $\mathbf{d}$. $\mathbf{h}$ Left: The mean PPR was not significantly different between any time point following NAc-iLTD induction in the presence of $50 \mathrm{mM}$ EtOH and cyclotraxin B. Right: Representative traces for each time point. Insets: Representative traces of the first 5 min (dark) and final 5 min (light) of the experiment. Scale bars: 200 pA, 200 ms. Data are represented as mean \pm SEM 


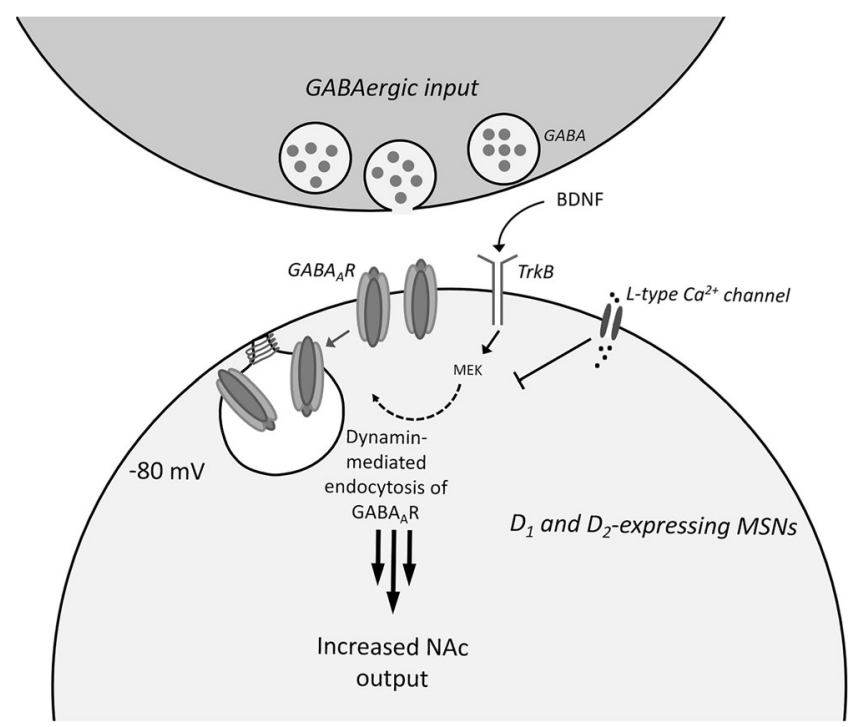

Fig. 5 Proposed mechanism of NAc-iLTD. D1- and D2-expressing MSNs undergo NAc-iLTD through the activation of postsynaptic TrkB receptors following BDNF release. TrkB signaling enhances MEK activity, which leads to the depression of the synapse in a dynamindependent manner, possibly through the internalization of $G_{A B A}$ receptors. NAc-iLTD occurs when MSNs are in the hyperpolarized down state, and activation of the L-type $\mathrm{Ca}^{2+}$ channel can abolish this plasticity. We propose that NAc-iLTD disinhibits a subset of MSNs residing in the down state to enhance NAc output

acetaldehyde did not induce iLTD in NAc MSNs (IPSC amplitude = $97.73 \pm 11.46 \%$ of baseline, $t=0.19, \mathrm{df}=7, p=0.85$, paired $t$-test, Figure $\mathrm{S} 1 \mathrm{H})$. Further, delivering eLFS in the presence of acetaldehyde $(1 \mu \mathrm{M})$ did not induce NAc-iLTD (IPSC amplitude = $125.2 \pm 15.55 \%$ of baseline, $t=1.62, \mathrm{df}=5, p=0.17$, paired $t$-test, Figure S1I), nor did synaptic depression occur following eLFS and subsequent acetaldehyde removal (IPSC amplitude in acetaldehyde $=122.0 \pm 10.46 \%$ of baseline, IPSC amplitude in $\mathrm{aCSF}=$ $110.6 \pm 15.06, t=1.18, \mathrm{df}=7, p=0.28$, paired $t$-test, Figure S1J).

\section{DISCUSSION}

We find that NAc-iLTD is dependent upon TrkB activation, is voltage-dependent, and is enhanced by the presence of EtOH at concentrations that correspond with physiologically relevant levels of intoxication [24]. Taken together, these results support the notion that accumbal output is under plastic control through the BDNF-TrkB signaling system and may be important for the encoding of alcohol reward (Fig. 5).

Here, we demonstrate that inhibitory inputs onto NAc MSNs undergo iLTD. The question remains of which inhibitory input(s) onto MSNs undergo NAc-iLTD. Several candidate inhibitory inputs exist to underlie this depression, including the ventral pallidum, fast-spiking interneurons, neighboring MSNs, and midbrain dopamine neurons. As subsets of midbrain dopaminergic inputs corelease GABA or BDNF onto MSNs $[25,26]$, it is also possible that these neurons are the source of BDNF. However, future work is needed to determine whether midbrain- or prefrontal cortexderived BDNF [27] mediate NAc-iLTD.

In contrast to the direct induction of iLTD by EtOH in the dorsal striatum [28], in the $\mathrm{NAc} \mathrm{EtOH}$ alone does not induce synaptic depression but instead augments NAc-iLTD. EtOH differentially alters BDNF expression depending on the brain region, the dose of $\mathrm{EtOH}$ and the time interval following EtOH exposure [29-31]. Given that our experiments involve the acute application of EtOH to NAc slices only minutes before NAc-iLTD induction, it is unlikely that our findings of EtOH-induced enhanced depression of IPSC amplitude following NAc-iLTD induction are due to an increase in BDNF expression. It is possible however, that $\mathrm{EtOH}$ augments BDNF release. Alternatively, EtOH may boost signaling downstream of postsynaptic MSN TrkB activation. Consistent with this idea, Ben Hamida and colleagues (2012) demonstrated that activity of the small GTP binding protein, $\mathrm{H}$-Ras increases in the $\mathrm{NAc}$ following acute exposure to EtOH. Further, suppression of $\mathrm{H}$ Ras activation in the NAc significantly decreases EtOH consumption, suggesting $\mathrm{H}$-Ras and the resulting signaling cascade are key modulators in the rewarding effects of EtOH. The Ras family of proteins is upstream of MEK and downstream of TrkB activation [1]. These findings position this family of proteins as potential permissive molecular signals underlying $\mathrm{EtOH}$ modulation of NAciLTD and a possible interventional target for the reinforcing effects of EtOH [32]. Further work is necessary to link H-Ras and NAc-iLTD.

While direct- and indirect-pathway-specific activity and plastic events are linked to reward and aversion [18, 33, 34], we did not observe pathway specificity in our slice electrophysiology experiments. This does not rule out the possibility that NAc-iLTD is induced preferentially at one pathway or another in vivo. Assuming there is no pathway specificity in vivo, this is reminiscent of the pathway non-specific, serotonin-mediated LTD at NAC excitatory synapses [16] that encodes social reward [35]. Such global disinhibition of the structure by NAc-iLTD could act in concert with pathway-specific plasticity mechanisms at excitatory synapses. At face value, the present data support the notion that global disinhibition of the NAc may encode reward and that augmentation of this mechanism by EtOH may modulate alcohol drinking behavior. As such, NAc-iLTD represents a starting point from which to devise treatment strategies for disorders of reward and aversion, such as addiction and depression.

\section{FUNDING}

This work was supported by the Alcoholic Beverage Medical Research Foundation/The Foundation for Alcohol Research, National Institute on Alcohol Abuse and Alcoholism grants K22AA021414, R01AA024845 (B.N.M.) and F31AA024683 (M.H.P.) and a Whitehall Foundation grant 2014-12-68 (B.N.M.).

\section{ACKNOWLEDGEMENTS}

The authors thank all current and previous lab members who contributed to this project.

\section{AUTHOR CONTRIBUTIONS}

M.H.P. and B.N.M. conceived experiments. M.H.P., K.E.P., P.N.M., C.M., H.Q., M.S.P., B.M.R. and B.N.M. performed experiments. M.H.P. and B.N.M. wrote the manuscript with help from K.E.P., P.N.M., C.M., H.Q., M.S.P., and B.M.R. M.H.P. and B.N.M. secured funding.

\section{ADDITIONAL INFORMATION}

Supplementary Information accompanies this paper at (https://doi.org/10.1038/ s41386-019-0341-8).

Conflict of interest: The authors declare no competing interest.

Publisher's note: Springer Nature remains neutral with regard to jurisdictional claims in published maps and institutional affiliations.

\section{REFERENCES}

1. Russo SJ, Mazei-Robison MS, Ables JL, Nestler EJ. Neurotrophic factors and structural plasticity in addiction. Neuropharmacology. 2009;56(Suppl 1):73-82.

2. Schultz W. Reward functions of the basal ganglia. J Neural Transm. 2016; 123:679-93.

3. Sesack SR, Grace AA. Cortico-Basal Ganglia reward network: microcircuitry. Neuropsychopharmacology. 2010;35:27-47. 
4. Grueter BA, Rothwell PE, Malenka RC. Integrating synaptic plasticity and striatal circuit function in addiction. Curr Opin Neurobiol. 2012;22:545-51.

5. Luscher C, Malenka RC. Drug-evoked synaptic plasticity in addiction: from molecular changes to circuit remodeling. Neuron. 2011;69:650-63.

6. Nisenbaum ES, Berger TW. Functionally distinct subpopulations of striatal neurons are differentially regulated by GABAergic and dopaminergic inputs-I. In vivo analysis. Neuroscience. 1992;48:561-78.

7. Kerr JN, Plenz D. Action potential timing determines dendritic calcium during striatal up-states. J Neurosci. 2004;24:877-85.

8. O'Donnell P, Grace AA. Synaptic interactions among excitatory afferents to nucleus accumbens neurons: hippocampal gating of prefrontal cortical input. J Neurosci. 1995;15(5 Pt 1):3622-39.

9. Wilson CJ, Kawaguchi Y. The origins of two-state spontaneous membrane potential fluctuations of neostriatal spiny neurons. J Neurosci. 1996;16:2397-410.

10. Carter AG, Sabatini BL. State-dependent calcium signaling in dendritic spines of striatal medium spiny neurons. Neuron. 2004;44:483-93.

11. Kreitzer AC, Malenka RC. Dopamine modulation of state-dependent endocannabinoid release and long-term depression in the striatum. J Neurosci. 2005;25:10537-45.

12. Mathur BN, Tanahira C, Tamamaki N, Lovinger DM. Voltage drives diverse endocannabinoid signals to mediate striatal microcircuit-specific plasticity. Nat Neurosci. 2013;16:1275-83

13. Wright WJ, Schluter OM, Dong Y. A feedforward inhibitory circuit mediated by CB1-expressing fast-spiking interneurons in the nucleus accumbens. Neuropsychopharmacology. 2017;42:1146-56.

14. Matyas F, Yanovsky Y, Mackie K, Kelsch W, Misgeld U, Freund TF. Subcellular localization of type 1 cannabinoid receptors in the rat basal ganglia. Neuroscience. 2006;137:337-61.

15. Davis MI, Crittenden JR, Feng AY, Kupferschmidt DA, Naydenov A, Stella N, et al. The cannabinoid-1 receptor is abundantly expressed in striatal striosomes and striosome-dendron bouquets of the substantia nigra. PLoS ONE. 2018;13: e0191436.

16. Mathur BN, Capik NA, Alvarez VA, Lovinger DM. Serotonin induces long-term depression at corticostriatal synapses. J Neurosci. 2011;31:7402-11.

17. Luikart BW, Nef S, Shipman T, Parada LF. In vivo role of truncated trkb receptors during sensory ganglion neurogenesis. Neuroscience. 2003;117:847-58.

18. Lobo MK, Covington HE 3rd, Chaudhury D, Friedman AK, Sun H, Damez-Werno D, et al. Cell type-specific loss of BDNF signaling mimics optogenetic control of cocaine reward. Science. 2010;330:385-90.

19. Kupferschmidt DA, Cody PA, Lovinger DM, Davis MI. Brain BLAQ: post-hoc thicksection histochemistry for localizing optogenetic constructs in neurons and their distal terminals. Front Neuroanat. 2015;9:6.

20. Atwood BK, Lovinger DM, Mathur BN. Presynaptic long-term depression mediated by Gi/o-coupled receptors. Trends Neurosci. 2014;37:663-73.
21. Yin $\mathrm{HH}$, Davis MI, Ronesi JA, Lovinger DM. The role of protein synthesis in striatal long-term depression. J Neurosci. 2006;26:11811-20.

22. Hewitt SA, Bains JS. Brain-derived neurotrophic factor silences GABA synapses onto hypothalamic neuroendocrine cells through a postsynaptic dynaminmediated mechanism. J Neurophysiol. 2006;95:2193-8.

23. Patton MH, Padgett KE, McKeon PN, Lu SG, Abrams TW, Mathur BN. An Aplysialike synaptic switch for rapid protection against ethanol-induced synaptic inhibition in a mammalian habit circuit. Neuropharmacology. 2019;144:1-8.

24. Lovinger DM, Roberto M. Synaptic effects induced by alcohol. Curr Top Behav Neurosci. 2013;13:31-86.

25. Tritsch NX, Oh WJ, Gu C, Sabatini BL. Midbrain dopamine neurons sustain inhibitory transmission using plasma membrane uptake of GABA, not synthesis. eLife. 2014;3:e01936.

26. Wook Koo J, Labonte B, Engmann O, Calipari ES, Juarez B, Lorsch Z, et al. Essential role of mesolimbic brain-derived neurotrophic factor in chronic social stressinduced depressive behaviors. Biol Psychiatry. 2016;80:469-78.

27. Altar CA, Cai N, Bliven T, Juhasz M, Conner JM, Acheson AL, et al. Anterograde transport of brain-derived neurotrophic factor and its role in the brain. Nature. 1997;389:856-60.

28. Patton MH, Roberts BM, Lovinger DM, Mathur BN. Ethanol disinhibits dorsolateral striatal medium spiny neurons through activation of a presynaptic delta opioid receptor. Neuropsychopharmacology. 2016;41:1831-40.

29. Jeanblanc J, He DY, Carnicella S, Kharazia V, Janak PH, Ron D. Endogenous BDNF in the dorsolateral striatum gates alcohol drinking. J Neurosci. 2009; 29:13494-502.

30. Orru A, Caffino L, Moro F, Cassina C, Giannotti G, Di Clemente A, et al. Contingent and non-contingent recreational-like exposure to ethanol alters BDNF expression and signaling in the cortico-accumbal network differently. Psychopharmacology. 2016;233:3149-60.

31. Raivio N, Tiraboschi E, Saarikoski ST, Castren E, Kiianmaa K. Brain-derived neurotrophic factor expression after acute administration of ethanol. Eur J Pharmacol. 2012;687:9-13.

32. Ben Hamida S, Neasta J, Lasek AW, Kharazia V, Zou M, Carnicella S, et al. The small $\mathrm{G}$ protein $\mathrm{H}$-Ras in the mesolimbic system is a molecular gateway to alcohol-seeking and excessive drinking behaviors. J Neurosci. 2012; 32:15849-58.

33. Kravitz AV, Kreitzer AC. Striatal mechanisms underlying movement, reinforcement, and punishment. Physiology. 2012;27:167-77.

34. Ferguson SM, Eskenazi D, Ishikawa M, Wanat MJ, Phillips $P E$, Dong $Y$, et al. Transient neuronal inhibition reveals opposing roles of indirect and direct pathways in sensitization. Nat Neurosci. 2011;14:22-24.

35. Dolen G, Darvishzadeh A, Huang KW, Malenka RC. Social reward requires coordinated activity of nucleus accumbens oxytocin and serotonin. Nature. 2013;501:179-84. 